\title{
Detection of background thermal neutrons in a modified low-background germanium gamma-ray spectrometer
}

\author{
Jerzy W. Mietelski ${ }^{1}$ (D)
}

Received: 30 July 2019 / Published online: 17 October 2019

(c) The Author(s) 2019

\begin{abstract}
The paper presents the detection of background neutrons using the $558.4 \mathrm{keV}$ gamma line emitted from excited ${ }^{114} \mathrm{Cd}$ nuclei after neutron induced processes. Stable cadmium and $60 \mathrm{~L}$ water moderator were placed inside low background shield of high purity germanium (HPGe) based spectrometer. The method was applied to study diurnal mean variation of background neutron flux. For this purpose $1 \mathrm{~h}$ gamma background spectra of modified HPGe spectrometer were collected subsequently for 50.5 days and then summed in 24-h-cycle. Results for the $558.4 \mathrm{keV}$ line are presented along with those of main background lines. The total gamma-ray spectrum was also analysed and results are presented and discussed. No cyclic structure was noticed for all examited lines but $2223 \mathrm{keV}$, for which some day-night effect is suggested to exist. Test of another moderator made of $108 \mathrm{~kg}$ of graphite was done, but the results obtained with water are more promising.
\end{abstract}

Keywords Gamma-ray spectrometer $\cdot$ Neutron capture in cadmium $\cdot$ Neutron moderation $\cdot$ Neutron background $\cdot$ Gammaray background

\section{Introduction}

Neutrons, as non-ionizing particles are detectable indirectly by secondary processes. As active detectors the most popular are proportional counters or ionizing chambers modified using thermal neutron sensitive materials like ${ }^{3} \mathrm{He},{ }^{6} \mathrm{Li},{ }^{10} \mathrm{~B}$ or ${ }^{235} \mathrm{U}$. Thus, the detection occurs due to specific nuclear reactions, which take place inside counter:

- Helium counter: ${ }^{1} n+{ }^{3} \mathrm{He} \rightarrow{ }^{3} \mathrm{H}+{ }^{1} \mathrm{H}$

- Lithium counter: ${ }^{1} n+{ }^{6} \mathrm{Li} \rightarrow{ }^{3} \mathrm{He}+{ }^{4} \mathrm{He}$

- $\mathrm{BF}_{3}$ or B lined counter: ${ }^{1} n+{ }^{10} \mathrm{~B} \rightarrow{ }^{4} \mathrm{He}+{ }^{7} \mathrm{Li}$

- Uranium counter: ${ }^{1} n+{ }^{235} \mathrm{U} \rightarrow$ fission

The second class of active detectors is based on elastic scattering (proton recoil), which is sensitive to fast neutrons. They are filled with hydrogen or hydrogen rich material.

Other kinds of active detectors are modified scintillators (anthracene or other organic) sensitive to fast neutrons, and semiconductors like silicone detectors with $\mathrm{LiF}$ converters.

Jerzy W. Mietelski

jerzy.mietelski@ifj.edu.pl

1 Institute of Nuclear Physics Polish Academy of Sciences, Radzikowskiego 152, 31-342 Kraków, Poland
Next to active methods passive ones are widely used. They are based on neutron activation of different materials followed by gamma-ray spectrometry or they are dose meters as for instance thermoluminescence detectors (TLD) using lithium fluoride pellets (enriched with ${ }^{6} \mathrm{Li}$ ).

Eventually, since the neutron background at sea level is about $0.015 \mathrm{n} /\left(\mathrm{cm}^{2} \mathrm{~s}\right)$ [1] also neutron induced effects like inelastic neutron scattering with gamma-ray emission or radiative capture processes are observed in lowbackground gamma-ray spectrometry. In such processes gamma-ray quanta are emitted. Therefore, if these effects exists at reasonable intensities [2-6], they can be used for neutron detection. In Fig. 1 is presented an example of a low-background gamma-ray spectrum in which "neutron effects" are observed. The spectrum was collected with a low background gamma-ray spectrometer with active shield [7]. Neutron effects can be enhanced introducing materials with high cross sections for neutron induced gammaray emission. Even pure water can be used for this purpose (Fig. 2), due to the emission of $2223 \mathrm{keV}$ line from neutron capture by hydrogen $[3,7]$. There are, however, more efficient materials. One of these is cadmium [7], due to high cross section for thermal neutrons capture with emission of several gamma-ray lines, among them the $558.4 \mathrm{keV}$ line (Fig. 3). The $558.4 \mathrm{keV}$ gamma-ray line comes from the 


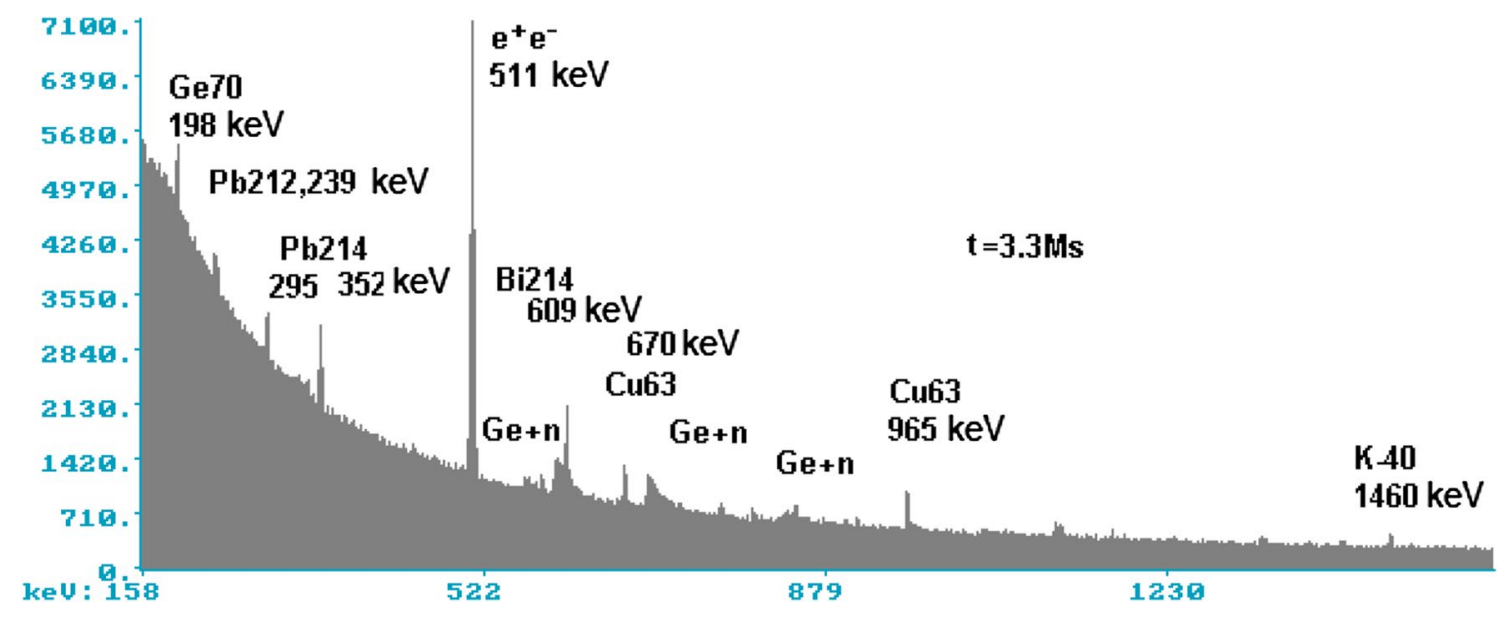

Fig. 1 Example of gamma-ray spectrum registered during more than a month (3.3 Ms) of measurement in shielded low background HPGe detector with composite shield $(15 \mathrm{~cm}$ of lead, $\mathrm{Cu}$ lining and
$70 \times 70 \mathrm{~cm}$ multiwire Charpak chamber as active veto) [7]. The spectral lines produced in inelastic scattering of neutrons on germanium and other neutron effects are visible [2]

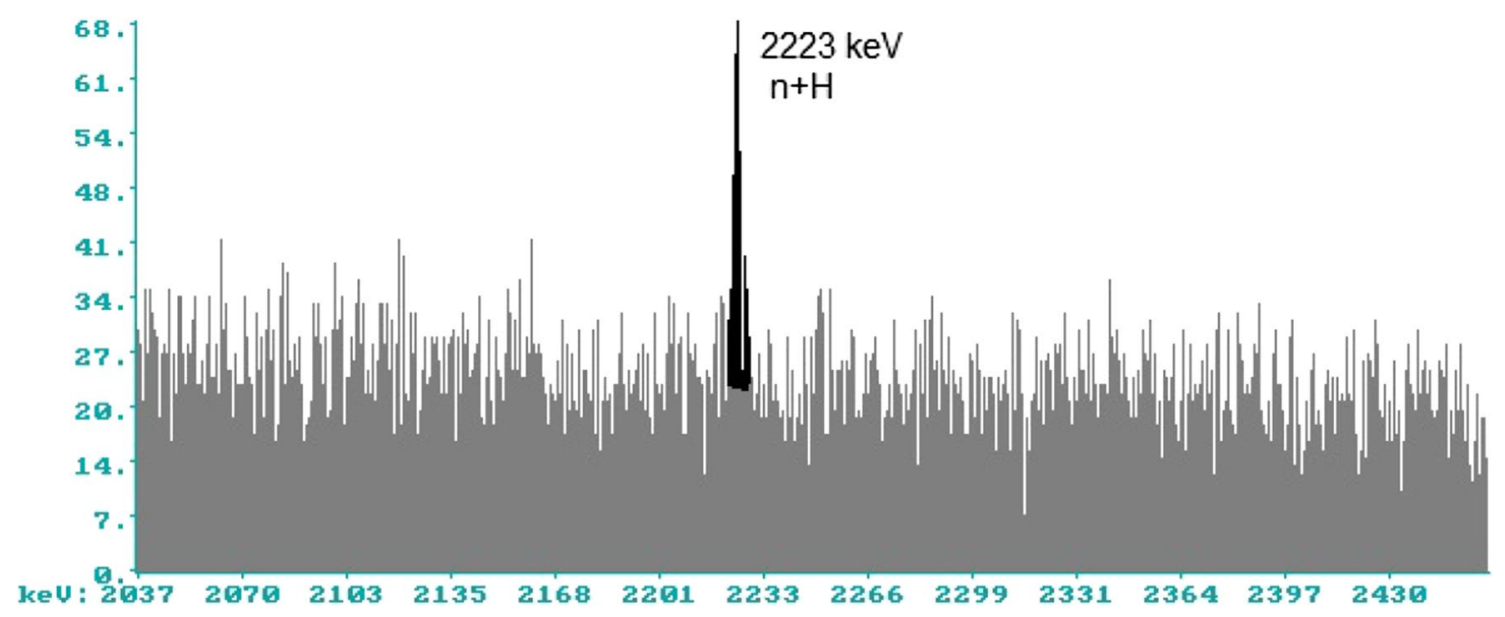

Fig. 2 The $2223 \mathrm{keV}$ gamma line of neutron capture by hydrogen observed for water sample (0.5 L in Marinelli beaker) in low background gamma spectrometer with active shield [7] during 11 days lasting measurement

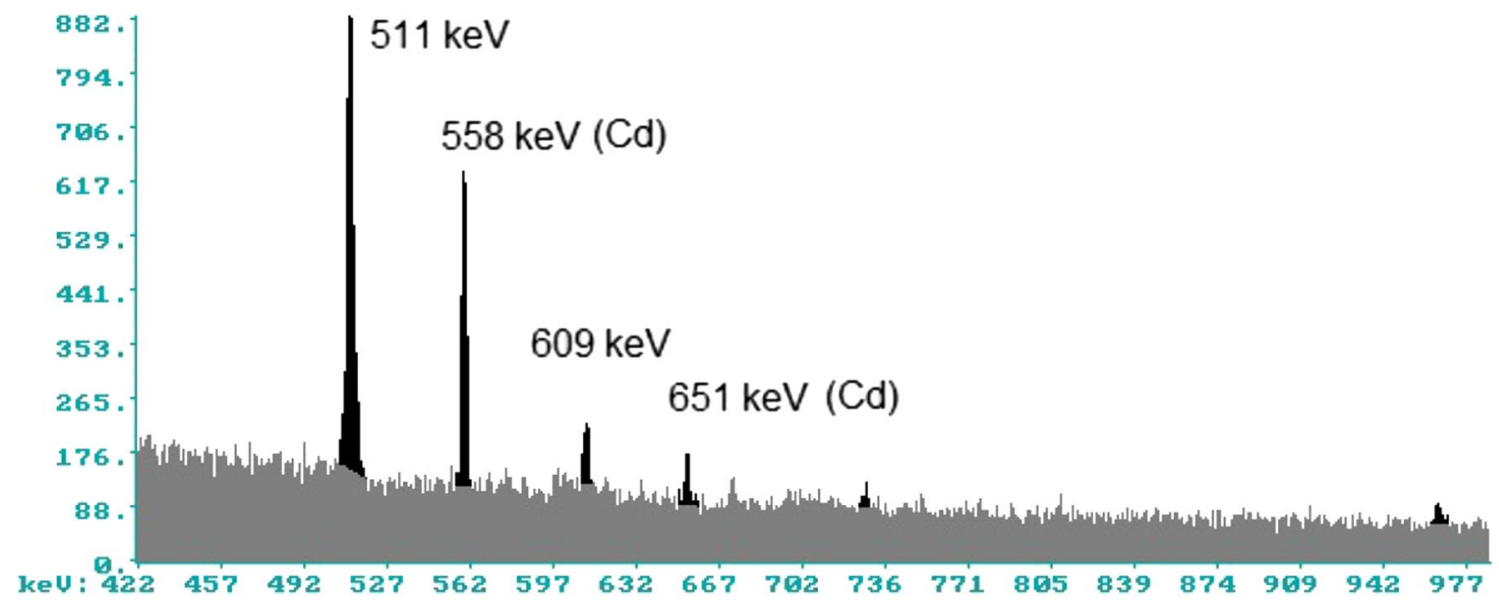

Fig. 3 The gamma line of neutron capture by cadmium observed for Marinelli beaker with cadmium inner lining filled with paraffin with water inside shield in role of additional moderator registered in low level gamma spectrometer equipped with active shield [7] 
de-excitation of the first excited level of a stable ${ }^{114} \mathrm{Cd}$ [8]. It is usually observed in decays of ${ }^{114} \mathrm{In}$ or ${ }^{114} \mathrm{Ag}$, however, this level can be populated also in neutron induced processes like ${ }^{114} \mathrm{Cd}\left(\mathrm{n}, \mathrm{n}^{\prime}\right){ }^{114} \mathrm{Cd},{ }^{113} \mathrm{Cd}(\mathrm{n}, \gamma){ }^{114} \mathrm{Cd}$ or ${ }^{113} \mathrm{Cd}(\mathrm{n}, \mathrm{p}){ }^{114} \mathrm{Ag}$, followed by beta decay of the latter (Fig. 4).

\section{Methods}

The general idea of a modifying low background germanium spectrometer to enhance the signal from environmental background neutrons was proposed and tested many years ago [7]. The principle of modification is simple: some cadmium and moderator are placed inside the low background shield. In current, modified version a $2 \mathrm{~mm}$ thick cadmium foil $(30 \times 10 \mathrm{~cm})$ was wrapped around (Fig. 5). Another $2 \mathrm{~mm}$ thick cadmium foil $(10 \times 10 \mathrm{~cm})$ was placed on a top of end-cap. The HPGe detector was made [9] at the home Institute of Nuclear Physics (INP) workshop using a germanium crystal (purchased from UMICORE, Belgium, of $\sim 50 \mathrm{~mm}$ diameter and $\sim 50 \mathrm{~mm}$ height). The cryostat of the detector is made of ultrapure aluminum by Baltic Scientific Instruments (BSI), having $\mathrm{U}$ and Th impurities levels at $1 \times 10^{-9} \mathrm{~g} / \mathrm{g}$ range [9] and equipped with composite carbon fibre window. The detector was in standard lead shield of $10 \mathrm{~cm}$ thick bricks with $50 \times 50 \times 50 \mathrm{~cm}$ shielded space (mass 2.2 t, Fig. 6). Besides cadmium a moderator was placed inside the shield. Various configurations of moderator were tested. The final one consists of $60 \mathrm{~L}$ of water put in 12 plastic canisters of $5 \mathrm{~L}$ volume each (Fig. 5). In this
Fig. 4 The illustration for emission of $558 \mathrm{keV}$ gamma line by exited ${ }^{114} \mathrm{Cd}$ stable nuclei in chosen processes induced by neutrons $[4,13]$
Fig. 5 Details of arrangements of passive elements inside of gamma ray spectrometer shield: cadmium plate wrapped around detector and covering it from top, setup of twelve plastic containers filled with water around detector in two layers, setup of five graphite cylinders
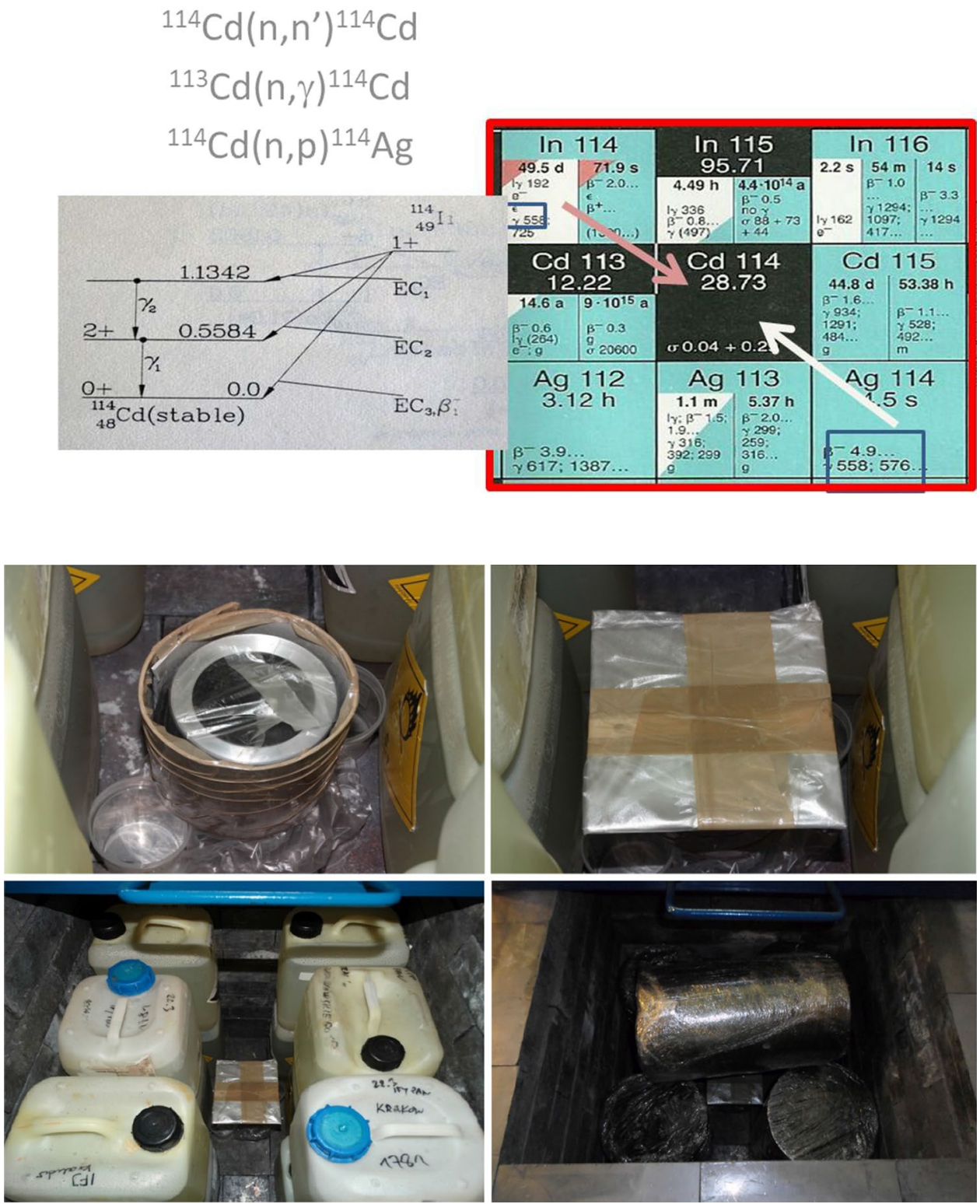


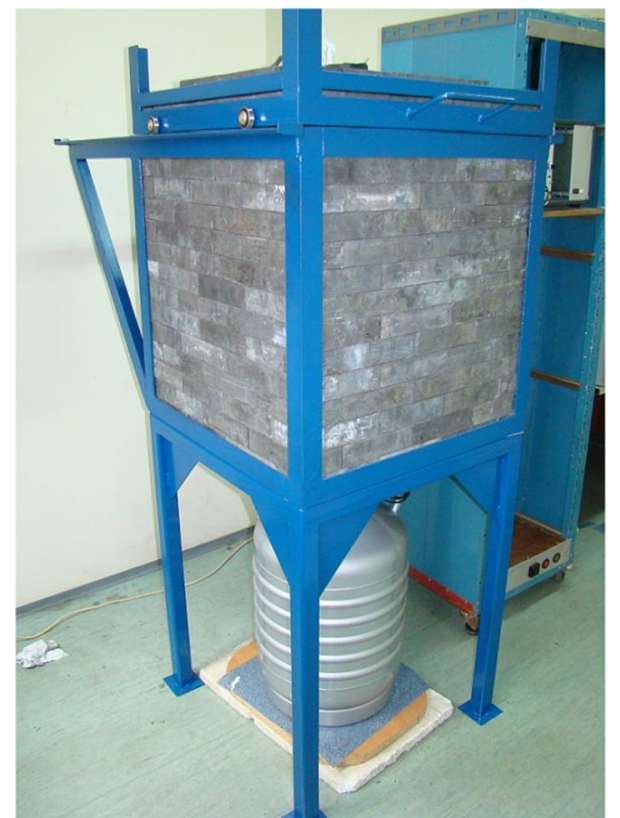

Fig. 6 The general view of detector and lead shield

configuration background spectra were collected in automatic mode, recording separately every hour a spectrum (namely $3590 \mathrm{~s}$ of counting and $10 \mathrm{~s}$ break). The acquisition system consists of standard NIM electronics including NIM crate (by FAST, Germany), an amplifier, model 2020 and HV power supply, model 3106 (Canberra, USA) and MCA Tukan-USB (by NCNR Świerk, Poland). Measurements were performed for 50.5 days from May to July 2014 . Then spectra were summed together for each hour of day, reducing number of spectra from 1212 to 24 . The aim was to check if there is any day cycle (day-night effect) of count rates in main background lines of spectrometer. Besides it, a total spectrum (with acquisition time of $\sim 4.35 \mathrm{Ms}$ ) from all single hour spectra was created as well. All the summing was performed by a code in Fortran. Another set of measurements were conducted with a different moderator inside shield. Namely, there were five graphite cylinders $(20 \mathrm{~cm}$ diameter, $32 \mathrm{~cm}$ height, about $10 \mathrm{~L}$ of volume each) with total mass of $\sim 108 \mathrm{~kg}$. They were placed inside the shield (Fig. 5) around the detector as moderator, four were standing in the corners of the shield and one was lying on them covering detector from top.

\section{Results and discussion}

The results for the total-50-days gamma-ray spectrum are shown in Table 1 and in Fig. 7. All presented uncertainties are just counting statistics ones. The gamma-ray lines in the spectrum, presented in Table 1, were identified based on data given in literature [10-12]. Please note the absence of relatively intense lines from thorium series like $239 \mathrm{keV}$ of ${ }^{212} \mathrm{~Pb}, 338 \mathrm{keV}$ of ${ }^{228} \mathrm{Ac}$ - or $583 \mathrm{keV}$ of ${ }^{208} \mathrm{Tl}$, also the absence of some from uranium series like $1001 \mathrm{keV}$ of ${ }^{234 \mathrm{~m}} \mathrm{~Pa}$, present in typical low background gamma-ray spectra [12]. They were also not present in measurements performed underground (at depth of $\sim 1 \mathrm{~km}$ inside a gallery within salt deposit of Sieroszowice copper mine) with the same detector [9]. This is the result of low level of Th and $\mathrm{U}$ traces in BSI low cryostat of detector. This confirms, that the high energy $(2614 \mathrm{keV})$ line of ${ }^{208} \mathrm{Tl}$ comes from outside of the shield. Apparently more difficult was removing traces of radon $\left.{ }^{222} \mathrm{Rn}\right)$ daughters from background, since the shield was not tight enough to prevent their diffusive penetration into shield, however that can be easily improved by introducing of $\mathrm{LN}_{2}$ vapors flush into the inner space of shield.

The results obtained for single hours in day are shown in the Figs. 8, 9 and 10. Figure 8 shows a diurnal changes in numbers count in the background for the main spectral lines from radon $\left({ }^{222} \mathrm{Rn}\right)$ progeny: two lines of ${ }^{214} \mathrm{~Pb}(295$ and $352 \mathrm{keV})$ and three lines of ${ }^{214} \mathrm{Bi}(609,1120$ and $1764 \mathrm{keV})$. The drawings present also the average values obtained for the summary spectrum (as presented in Table 1). Shown are also residual count rates. One cannot observe any systematic changes of daily average values-of the intensity of all the lines since they show only random scatter around average values. This means that that no difference between working hours and rest of the day was noticed.

Figure 9 shows the daily changes in number of counts in the background for the main spectral lines from radionuclides permanently present in the surroundings of the spectrometer emitting photons at high energies, for which $10 \mathrm{~cm}$ lead shield is likely not sufficiently thick to eliminate complete external radiation: ${ }^{40} \mathrm{~K}(1461 \mathrm{keV})$ and ${ }^{208} \mathrm{Tl}$ $(2615 \mathrm{keV})$. The drawings present also the average values obtained for the summary spectrum (as presented in Table 1). Again, one cannot observe any systematic changes of daily average values-of the intensity of all the lines since they show only random scatter are around average values, but in this case this was an expected result. Also the residual count rates confirms statistical scattered pattern only.

Figure 10 shows a diurnal changes in number of counts in the background for the main gamma-ray spectral lines of photons emitted as a result of interactions with particles of the secondary cosmic rays, such as muons and neutrons. It should be noted, that the cosmic radiation is perhaps not the sole source of positrons and neutrons, however, it can be expected that this is the dominant source. The peak $511 \mathrm{keV}$ comes from the annihilation of positrons with electrons. Positrons are produced in electromagnetic avalanches arising from interactions of cosmic muons with all surrounding matter (air, shield materials, detector itself), but they may also come from beta plus emitters present in traces (as activation 
Table 1 Spectral gamma ray lines present in the combined spectrum collected during $4,351,080 \mathrm{~s}$ ( $\sim 50.5$ days $)$ of the background investigation of the spectrometer

\begin{tabular}{|c|c|c|c|c|c|c|}
\hline E (kev) obser. & $S$ & $\mathrm{dS}$ & $\mathrm{S} / \mathrm{t}$ & $\mathrm{dS} / \mathrm{S}$ & Identification $[1,2]$ & $\mathrm{E}(\mathrm{keV}) \mathrm{ref}$ \\
\hline 139.3 & 486 & 297 & 0.000112 & 0.61 & $\mathrm{n}+\mathrm{Ge}$ & 139.7 \\
\hline 242.7 & 4764 & 359 & 0.001095 & 0.075 & $\mathrm{~Pb}-214$ & 241.9 \\
\hline 295.6 & 8069 & 320 & 0.001855 & 0.040 & $\mathrm{~Pb}-214$ & 295.2 \\
\hline 352.0 & 14,156 & 289 & 0.003254 & 0.020 & $\mathrm{~Pb}-214$ & 351.9 \\
\hline 511.1 & 29,015 & 286 & 0.006669 & 0.0099 & $\mathrm{e}^{+} \mathrm{e}^{-}$ & 511 \\
\hline 558.8 & 10,922 & 196 & 0.002510 & 0.018 & $\mathrm{n}+\mathrm{Cd}$ & 558.4 \\
\hline 609.5 & 11,077 & 197 & 0.002546 & 0.018 & $\mathrm{Bi}-214$ & 609.2 \\
\hline 651.4 & 1814 & 155 & 0.000417 & 0.086 & $\mathrm{n}+\mathrm{Cd}$ & 651 \\
\hline 662.2 & 635 & 163 & 0.000146 & 0.26 & Cs- $137+\mathrm{Bi} 214$ & $661.7,665$ \\
\hline 693.4 & 240 & 102 & 0.000055 & 0.43 & $\mathrm{n}+\mathrm{Ge}$ & 693 \\
\hline 725.2 & 354 & 119 & 0.000081 & 0.34 & $\mathrm{n}+\mathrm{Cd}$ & 725 \\
\hline 768.5 & 1101 & 131 & 0.000253 & 0.12 & $\mathrm{Bi}-214$ & 768.4 \\
\hline 806.1 & 911 & 128 & 0.000209 & 0.14 & $\mathrm{Bi}-214+(\mathrm{n}+\mathrm{Cd})$ & 806.2 \\
\hline 910.3 & 541 & 147 & 0.000125 & 0.27 & Ac-228 & 911.1 \\
\hline 934.2 & 460 & 96 & 0.000106 & 0.21 & $\mathrm{Bi}-214$ & 934.1 \\
\hline 1120.1 & 2602 & 132 & 0.000598 & 0.051 & $\mathrm{Bi}-214$ & 1120.3 \\
\hline 1155.5 & 318 & 107 & 0.000073 & 0.33 & $\mathrm{Bi}-214$ & 1155.3 \\
\hline 1201.7 & 395 & 88 & 0.000098 & 0.22 & $\mathrm{DEn}+\mathrm{H}$ & 1201 \\
\hline 1209.0 & 331 & 94 & 0.000076 & 0.34 & $\mathrm{Bi} 214+(\mathrm{n}+\mathrm{Cd})$ & 1207.7 \\
\hline 1237.9 & 1119 & 119 & 0.000257 & 0.11 & $\mathrm{Bi}-214$ & 1238.1 \\
\hline 1279.9 & 336 & 97 & 0.000077 & 0.29 & $\mathrm{Bi}-214$ & 1281 \\
\hline 1363.8 & 503 & 102 & 0.000116 & 0.20 & $(\mathrm{n}+\mathrm{Cd})$ & 1364 \\
\hline 1377.6 & 542 & 86 & 0.000125 & 0.16 & $\mathrm{Bi}-214$ & 1377.7 \\
\hline 1401.4 & 537 & 92 & 0.000123 & 0.17 & $\mathrm{Bi}-214$ & 1401.5 \\
\hline 1408.0 & 357 & 87 & 0.000082 & 0.24 & $\mathrm{Bi}-214$ & 1408 \\
\hline 1461.3 & 4666 & 119 & 0.001072 & 0.026 & $\mathrm{~K}-40$ & 1460.8 \\
\hline 1509.1 & 407 & 82 & 0.000094 & 0.20 & $\mathrm{Bi}-214$ & 1509.2 \\
\hline 1592.3 & 455 & 82 & 0.000105 & 0.18 & DE Tl-208 & 1593 \\
\hline 1659.6 & 276 & 71 & 0.000064 & 0.26 & $\mathrm{Bi} 214$ & 1661.3 \\
\hline 1712.4 & 317 & 80 & 0.000073 & 0.26 & $\mathrm{SEn}+\mathrm{H}$ & 1712 \\
\hline 1730.5 & 488 & 78 & 0.000112 & 0.16 & $\mathrm{Bi}-214$ & 1729.6 \\
\hline 1764.4 & 2184 & 94 & 0.000502 & 0.043 & Bi-214 & 1764.5 \\
\hline 1847.6 & 218 & 69 & 0.000050 & 0.32 & $\mathrm{Bi}-214$ & 1847.4 \\
\hline 1964.8 & 94 & 45 & 0.000022 & 0.48 & Ac-228 & 1965.2 \\
\hline 2102.9 & 233 & 62 & 0.000054 & 0.27 & $\mathrm{Bi}-214$ & 2102.0 \\
\hline 2204.2 & 774 & 69 & 0.000178 & 0.089 & $\mathrm{Bi}-214$ & 2204.2 \\
\hline 2223.0 & 4129 & 94 & 0.000949 & 0.023 & $\mathrm{n}+\mathrm{H}$ & 2223 \\
\hline 2447.2 & 194 & 52 & 0.000045 & 0.27 & Bi-214 & 2247.9 \\
\hline 2456.6 & 184 & 48 & 0.000042 & 0.27 & Bi-214 & 2459.0 \\
\hline 2615.0 & 2386 & 79 & 0.000549 & 0.033 & Tl-208 & 2614.8 \\
\hline
\end{tabular}

$\mathrm{S}$ - recorded number of counts in given photo peak, $\mathrm{dS}$ - their uncertainties $(\mathrm{k}=1), \mathrm{t}$-measurement time, along with their interpretation [10-12] products) in construction material of the detector and shield. Moreover they comes also from pair production processes from any high energy gamma quanta. Neutrons, seen in the background on Earth, besides cosmogenic origin are also produced for example in the nuclear reactions like $(\alpha, n)$ but neutron flux from these processes is about three orders of magnitude lower than that from cosmic rays at sea level.
As in the previous two Figs. 8 and 9 are presented average values obtained from the total spectrum (as given in Table 1) together with residual count rates for different energies. For $511 \mathrm{keV}$ like in the previous viewgraphs, one cannot see any systematic changes daily average values. However it is a differently for the less intense gamma-ray line of $2223 \mathrm{keV}$ which is from deuterium formation. Here, the residual count 
Fig. 7 Summed gamma ray spectrum for 50.5 days of collection with $60 \mathrm{~L}$ water moderator and cadmium elements localized inside shield (see text for details). The energy (in keV) of main visible gamma lines are depicted

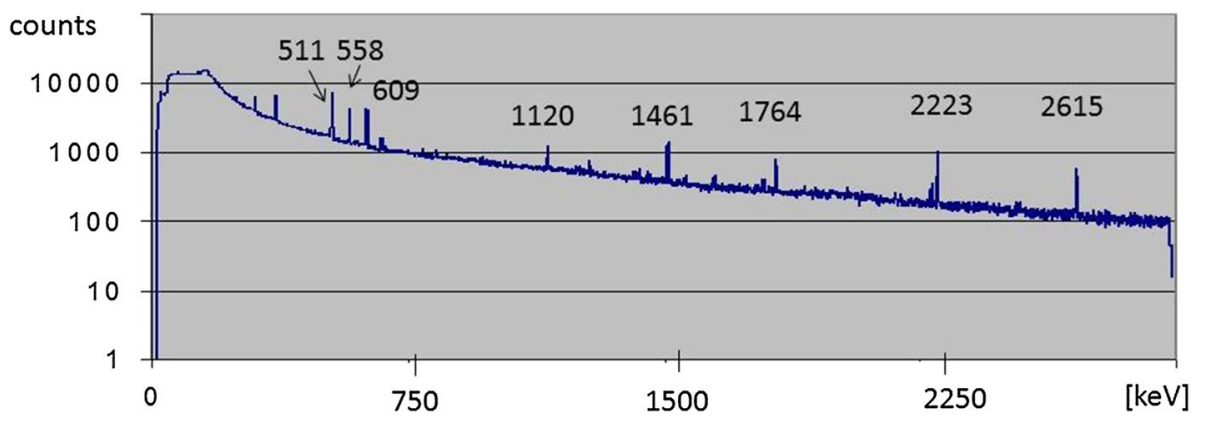

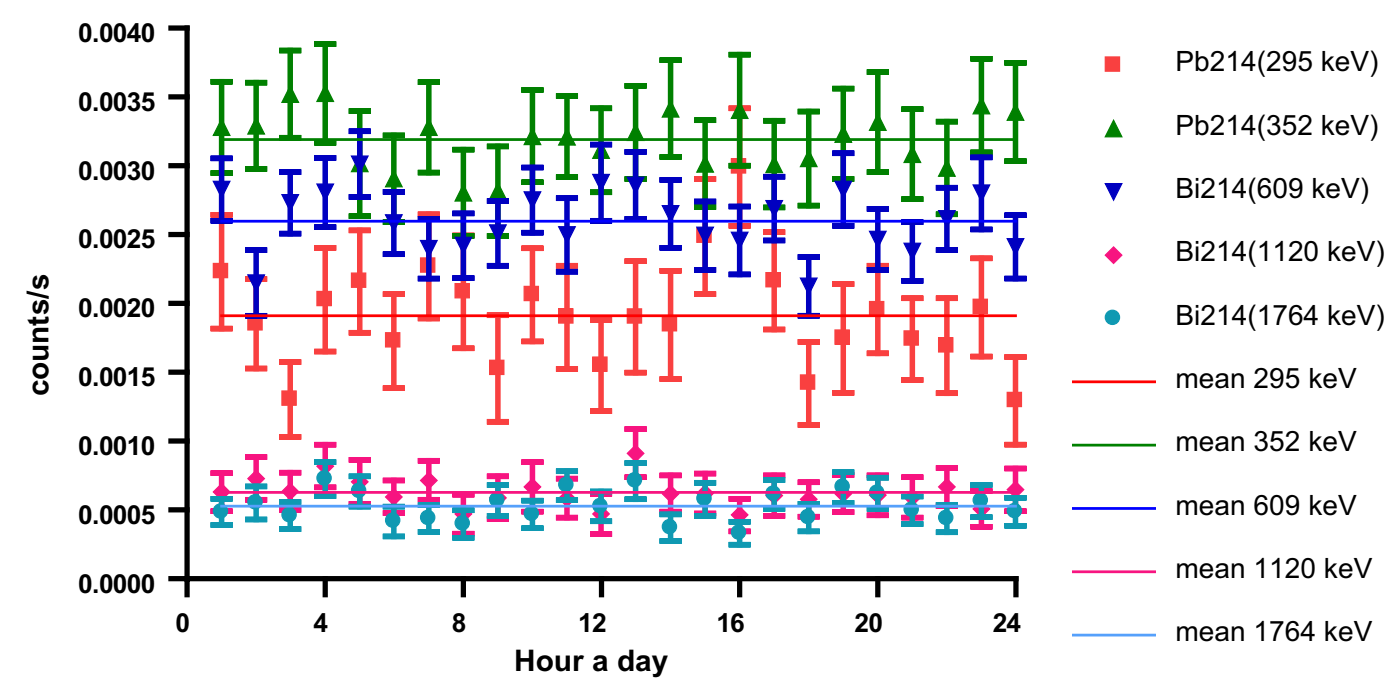

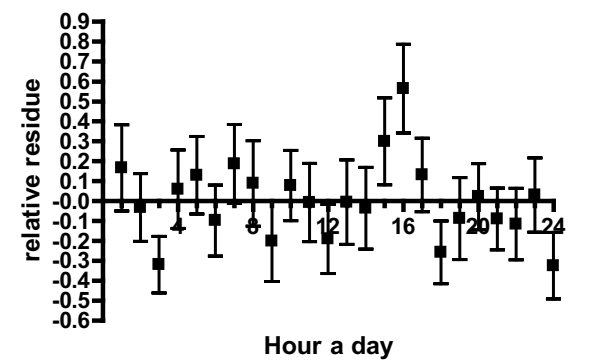

- $295 \mathrm{kev}$
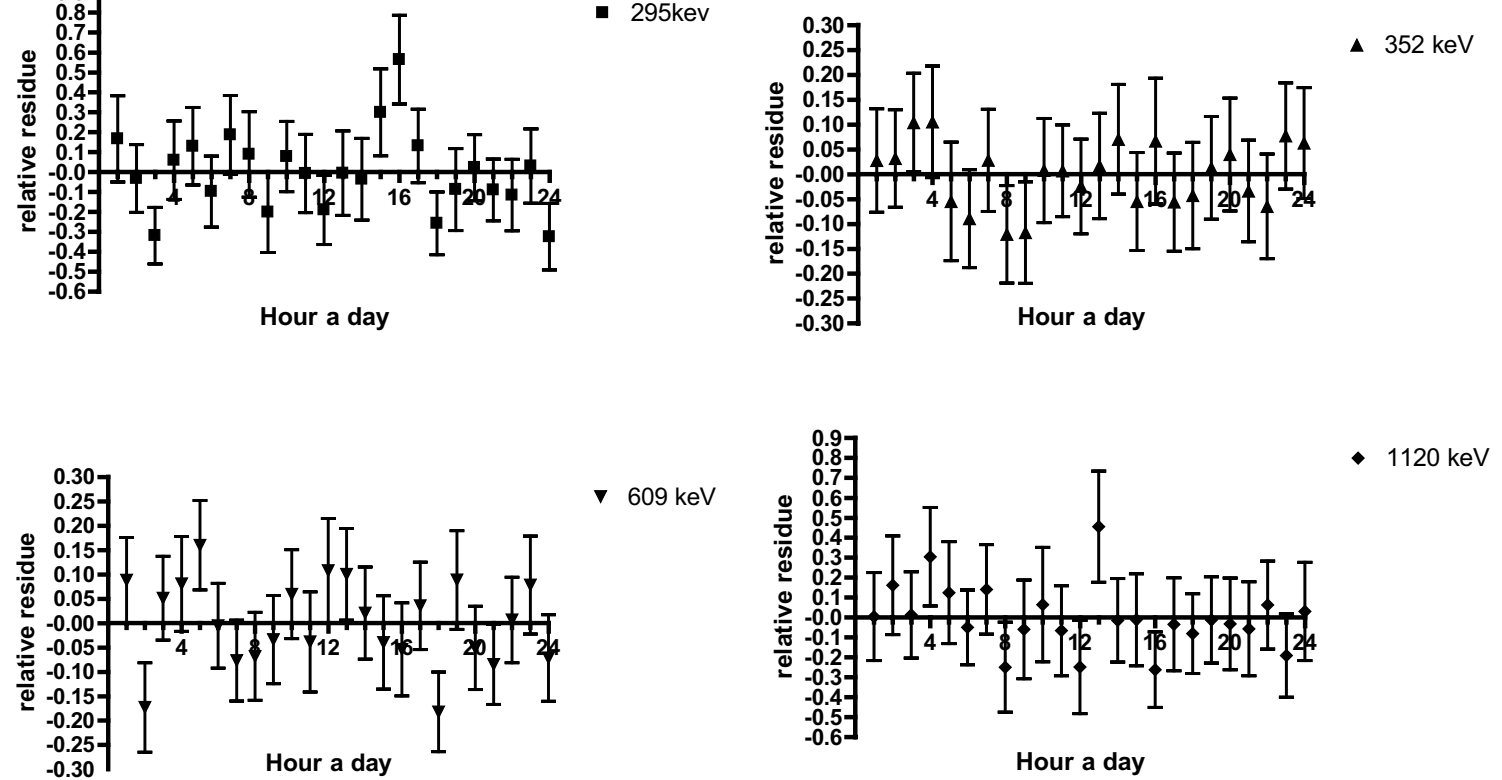

Fig. 8 The hour-a-day summed spectra results for main radon daughter gamma lines. Each spectrum as effectively collected for about $180,000 \mathrm{~s}$. Presented are counts rates (top) and their variation as rate residue (bottom) 

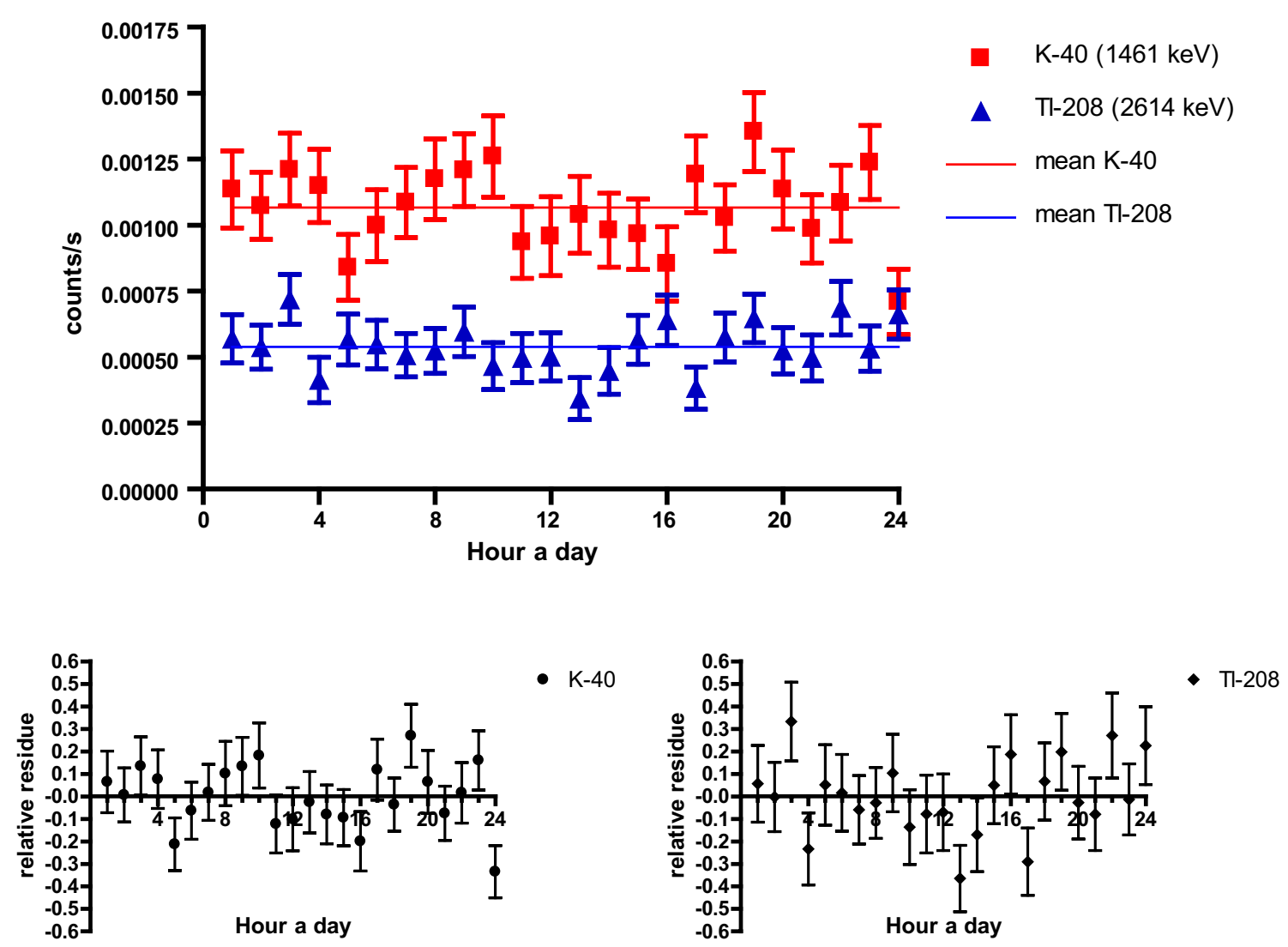

Fig. 9 The hour-a-day summed spectra results for high energy gamma lines of terrestrial radionuclides like ${ }^{40} \mathrm{~K}$ and ${ }^{208} \mathrm{Tl}$. Each spectrum as effectively collected for $\sim 180,000 \mathrm{~s}$. Presented are counts rates (top) and their variation as rate residue (bottom)

rates suggest the existence of lower production rate in night and higher during the day time. Results for $558.4 \mathrm{keV}$ peak do not show such variation, but also do not exclude possibility of existing of similar effect in future experiment done with better statistics.

The intensity of all the lines are around average values. The difficulty in observation of clear effect on counts rates in hour-a-day spectra could be the result of averaging of all effects by our procedure. It is known, that the neutron flux and well as the muon flux are functions of factors like humidity, air pressure or temperature $[14,15]$.

Results of comparison of water $(\sim 60 \mathrm{~L})$ and graphite $(\sim 108 \mathrm{~kg})$ moderators are shown in Table 2 . The results for graphite were obtained in a single measurement lasting about 10 days $(t=825,008)$ in beginning of 2019 , so 4 years later than the main experiment. One can notice that count rates in $511 \mathrm{keV}$ is different by 34\% in (higher for graphite), what can be explained by presence in graphite of traces of natural gamma-ray emitters, what is namely the case of Th resulting in additional counts in $511 \mathrm{keV}$ peak coming from $510.8 \mathrm{keV}$ gamma-ray line of ${ }^{208} \mathrm{Tl}$. The observed count rate for $558.4 \mathrm{keV}$ gamma-ray line from de-excitation of ${ }^{114} \mathrm{Cd}$ line diminished for graphite to $84 \%$ of that with water moderator. However the most important are the mentioned above traces of natural radioactivity isotopes in graphite, which increase the count rates in the main background lines by a factor $\sim 2.5$ (U series) or $\sim 4\left({ }^{40} \mathrm{~K}\right.$ ) as well as added no detectable earlier peaks from traces of Th series.

\section{Conclusions}

Although the diurnal variation of count rate for $558.4 \mathrm{keV}$ cadmium gamma-ray peak was not observed a kind of such effect is suggested for $2223 \mathrm{keV}$ deuterium production gamma-ray peak. All other analyzed lined revealed only statistical scattering pattern. Proposed simple modification of gamma spectrometer is an useful tool for monitoring of neutron flux at sea-level together with the cosmic muons flux (the main component in $511 \mathrm{keV}$ ). Moreover, the changes of mass and geometry of the moderator could be used to the study of composition of neutron spectra, which was not done here. Any possible application, in which there is a need of parallel measurements of prompt gamma-rays emitters and neutron flux, could make use of the proposed method or its variations. The 

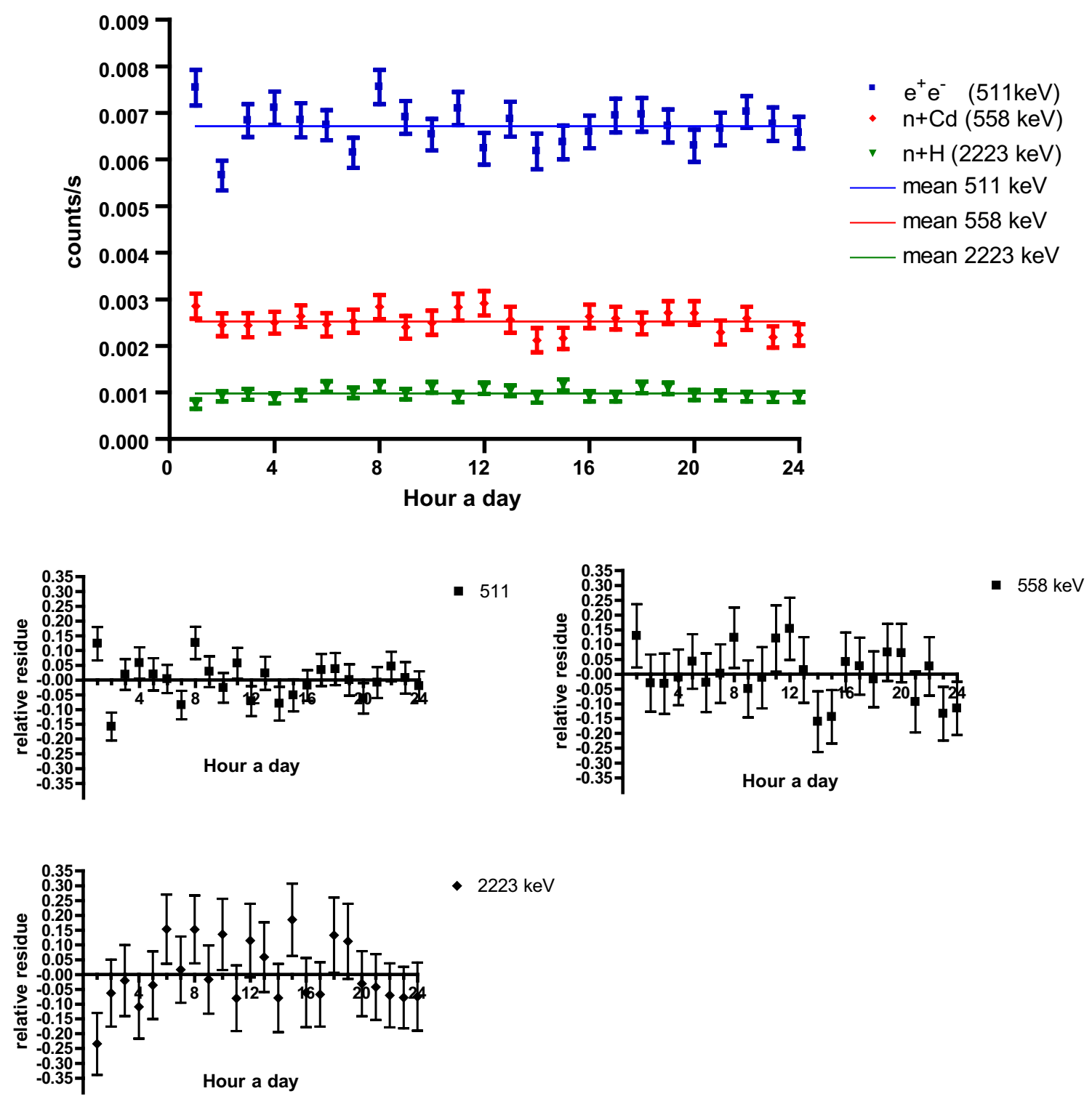

Fig. 10 The hour-a-day summed spectra results for gamma lines occurring mainly due to interaction with secondary cosmic particles like muons or neutrons in modified gamma spectrometer. Each spec-

Table 2 Comparison of intensity of chosen gamma-lines in spectrum for different moderator placed inside the spectrometer's lead shield: $60 \mathrm{~L}$ of water (" $\mathrm{H}_{2} \mathrm{O}$ [CPS]") or $108 \mathrm{~kg}$ of graphite ("C [CPS]")

\begin{tabular}{llll}
\hline $\mathrm{E}(\mathrm{keV})$ & $\mathrm{H}_{2} \mathrm{O}(\mathrm{CPS})$ & $\mathrm{C}(\mathrm{CPS})$ & $\mathrm{C} / \mathrm{H}_{2} \mathrm{O}$ \\
\hline 558 & 0.0025 & 0.0021 & 0.84 \\
511 & 0.0067 & 0.009 & 1.34 \\
1461 & 0.0011 & 0.0045 & 4.23 \\
352 & 0.0033 & 0.0076 & 2.34 \\
609 & 0.0026 & 0.0068 & 2.65 \\
\hline
\end{tabular}

trum as effectively collected for about $180,000 \mathrm{~s}$. Presented are counts rates (top) and their variation as rate residue (bottom)

future development of our setup and method are planned to explore its properties more deeply. Further modification of hardware is needed to create optimal conditions. Computer simulations are planned are planned to get absolute calibration of neutron flux. One idea is use of digital output, which would enable to sort data in any desired way.

Acknowledgements This work was supported by the National Centre for Research and Development, Poland (ERA-NET-ASPERA/03/2011).

Open Access This article is distributed under the terms of the Creative Commons Attribution 4.0 International License (http://creativeco mmons.org/licenses/by/4.0/), which permits unrestricted use, distribution, and reproduction in any medium, provided you give appropriate 
credit to the original author(s) and the source, provide a link to the Creative Commons license, and indicate if changes were made.

\section{References}

1. Gordon MS, Goldhagen P, Rodbell KP et al (2004) Measurement of the flux and energy spectrum of cosmic-ray induced neutrons on the ground. IEEE Trans Nucl Sci 51(6):3427-3434

2. Haines DK, Semkow TM, Khan AJ, Hoffman TJ, Meyer ST, Beach SE (2011) Muon and neutron-induced background in gamma-ray spectrometry. Nucl Instrum Methods. https://doi. org/10.1016/j.nima.2011.01.137

3. Jovancevic N, Krmar M (2011) Neutrons in the low-background Ge-detector vicinity estimated from different activation reactions. Appl Radiat Isot 69:629-635

4. Knezevic D, Jovancevic N, Krmar M, Petrovic J (2016) Modelling of neutron spectrum in the gamma spectroscopy measurements with Ge-detectors. Nucl Instrum Methods Phys Res A 833:23-26

5. Andelic B, Knezevic D, Jovancevic N, Krmar M, Petrovic J, Toth A, Medic Z, Hansman J (2017) Presence of neutrons in the lowlevel background environment estimated by the analysis of the $595.8 \mathrm{keV}$ peak. Nucl Instrum Methods Phys Res A 852:80-84

6. Krmar M, Hansman J, Jovancevic N, Lalovic N, Slivka J, Jokovic D, Maletic D (2013) A method to estimate a contribution of Ge $\left(n, n^{\prime}\right)$ reaction in the low-energy part of gamma spectra of HPGe detectors. Nucl Instrum Methods Phys Res A 709:8-11

7. Mietelski JW, Hajduk Z, Hajduk L, Jurkowski J (2004) Background effects observed with a low-level gamma-spectrometer with muon veto detector. In: International conference on isotopes in environmental studies, aquatic forum 2004, conference and symposium papers 26/P, Monaco, 25-29 Oct 2004, IAEACN-118/159, pp 538-542
8. Wallace G, McCallum GJ, Chapman NG (1971) The decay of ${ }^{114}$ Ag. Nucl Phys A 184:166-174

9. Polaczek-Grelik K, Kisiel J, Walencik-Łata A, Mietelski JW, Janowski P, Harańczyk M, Jurkowski J, Zalewska A, Kobziński J, Markowski P, Sadowski A (2016) Lead shielding efficiency from the gamma background measurements in the salt cavern of the Polkowice-Sieroszowice copper mine. J Radioanal Nucl Chem 308(3):773-780. https://doi.org/10.1007/s10967-015-4567-6

10. (2007) Database of prompt gamma rays from slow neutron capture for elemental analysis international atomic energy agency, Vienna

11. Nudat 2.5, National Nuclear Center, Brookhaven National Labs, USA. www.nndc.bnl.gov/nudat2

12. Bossew P (2005) A very long-term HPGe-background gamma spectrum. Appl Radiat Isot. https://doi.org/10.1016/j.aprad iso.2004.09.006

13. Magill J, Pfennig G, Dreher R, Sóti Z (2015) Karlsruhe chart of the nuclides, 9th edn. Nucleonica GmbH, Karlsruhe ISBN: 978-943868-04-3

14. Savic M, Dragic A, Veselinovic N, Udovicic V, Banjanac R, Jokovic D, Maletic D (2016) Effect of pressure and temperature corrections on muon flux variability at ground level and underground. In: XXV European cosmic ray symposium, Turin, Sept 4-9. arXiv :17001:00164v1

15. De Mendona RRS, Raulin J-P, Echer E, Makhmutov VS, Fernandez G (2013) Analysis of atmospheric pressure and temperature effects on cosmic ray measurements. J Geophys Res Space Phys 118:1403-1409. https://doi.org/10.1029/2012JA018026

Publisher's Note Springer Nature remains neutral with regard to jurisdictional claims in published maps and institutional affiliations. 